\title{
(2) OPEN ACCESS \\ Factors affecting the risk of relapsing-onset and progressive-onset multiple sclerosis
}

\author{
Anna Karin Hedström 다, ${ }^{1}$ Jan Hillert, ${ }^{1}$ Tomas Olsson, ${ }^{1}$ Lars Alfredsson ${ }^{2}$
}

\begin{abstract}
- Additional supplemental material is published online only. To view, please visit the journal online (http://dx. doi.org/10.1136/jnnp-2020 325688).
\end{abstract}

'Department of Clinical Neuroscience, Karolinska Institutet, Stockholm, Sweden ${ }^{2}$ Institute of Environmental Medicine, Karolinska Institutet, Stockholm, Sweden

Correspondence to Dr Anna Karin Hedström, Karolinska Institutet, Stockholm, Stockholm, Sweden; anna. hedstrom@ki.se

TO and LA contributed equally.

Received 19 November 2020 Revised 22 April 2021 Accepted 24 April 2021 Published Online First 13 May 202

\section{SLinked}

- http://dx.doi.org/10.1136/ jnnp-2020-325990

Check for updates

(C) Author(s) (or their employer(s)) 2021. Re-use permitted under CC BY. Published by BMJ.

To cite: Hedström AK, Hillert J, Olsson T, et al. J Neurol Neurosurg Psychiatry 2021:92:1096-1102.

\begin{abstract}
Objective It has been debated whether the different clinical disease courses in multiple sclerosis (MS) are the consequence of different pathogenic mechanisms, with distinct risk factors, or if all MS clinical phenotypes are variations of similar underlying disease mechanisms. We aimed to study environmental risk factors and their interactions with human leucocyte antigen DRB 1 * 15:01 with regards to relapsing-onset and progressive-onset MS.
\end{abstract}

Methods We used two Swedish population-based case-control studies, including 7520 relapsing-onset cases, 540 progressive-onset cases and 11386 controls matched by age, sex and residential area. Logistic regression was used to estimate ORs with $95 \%$ Cls for associations between the different MS phenotypes and a number of environmental and lifestyle factors. Interaction between the DRB1*15:01 allele and environmental risk factors was evaluated on the additive scale.

Results All environmental and lifestyle factors associated with risk of developing MS apply to both relapsing-onset and progressive-onset disease. Smoking, obesity and Epstein-Barr virus nuclear antigen-1 (EBNA-1) antibody levels were associated with increased risk of both MS phenotypes, whereas snuff use, alcohol consumption and sun exposure were associated with reduced risk. Additive interactions between DRB 1 *15:01 and smoking, obesity, EBNA-1 antibody levels and sun exposure, respectively, occurred to increase MS risk regardless of the clinical phenotype.

Interpretation Our finding that the same environmental and lifestyle factors affect both relapsingonset and progressive-onset MS supports the notion that the different clinical phenotypes share common underlying disease mechanisms.

\section{INTRODUCTION}

Multiple sclerosis (MS) is the most frequent demyelinating disease, characterised by a highly variable and mostly unpredictable disease course. MS typically starts as a relapsing remitting (RR) disease, characterised by recurring clinical symptoms followed by complete or partial recovery. Ultimately, the disease becomes progressive in a majority of patients and the clinical symptoms slowly cause progressive deterioration (secondary progressive MS). In a subset of patients, the disease is progressive from onset without distinct relapses (primary progressive MS) or with occasional superimposed relapses (progressive relapsing MS). ${ }^{1}$ Progressive-onset MS does not show the female predominance seen with relapsing onset $\mathrm{MS}^{2}$ and the onset of disease usually occurs later. ${ }^{3}$

It has long been debated whether the different clinical disease courses are due to different pathogenetic mechanisms or whether they present variants of a common disease process. ${ }^{4-7}$ The relapses in the RR disease course are believed to be the result of focal inflammatory demyelinating lesions, whereas the progressive course is dominated by diffuse grey and white matter atrophy and cortical demyelination. ${ }^{8}$ It is unclear whether the focal inflammatory lesions trigger the progressive phase of the disease or whether other mechanisms are responsible for the more subtle processes dominating the progressive phase.

The substantial differences in clinical presentation have also led to the question whether the disease courses have distinctive risk factors. Genetic variance is a proposed determinant of MS disease course, but no definite genetic differences have been found between relapsing and progressive onset MS. ${ }^{9}$ It has also been suggested that other factors than genetics may underlie the differences between the clinical phenotypes. However, few studies have investigated risk factors for MS by disease course. ${ }^{10}$ In the present report, we aimed to study environmental risk factors and their interactions with the main MS risk gene, the human leucocyte antigen (HLA)-DRB1*15:01 allele, with regards to relapsing-onset and progressive-onset MS.

\section{METHODS}

\section{Study design and data collection}

Epidemiological investigation of multiple sclerosis (EIMS) and genes and environment in multiple sclerosis (GEMS) are population-based, case-control studies with the main purpose to investigate the influence of genetic and environmental risk factors for MS. The study base comprised the Swedish general population aged $16-70$ years. In EIMS, cases with newly diagnosed MS were recruited from neurology clinics throughout the country, including all university hospitals. All cases were examined and diagnosed by a neurologist according to the McDonald criteria. ${ }^{11} 12$ For each case, we randomly selected two controls from the national population register, frequency matched for the case's age in 5-year age strata, sex and residential area. Reminders were sent to cases and controls who had not answered the questionnaire within 2, 4 and 6 weeks. Before a person was recorded as a nonresponder, he or she was also contacted by phone. The study period was April 2005 to June 2015. 


\begin{tabular}{|c|c|c|c|c|c|c|c|}
\hline Case-control status & Included & $\begin{array}{l}\text { Data on disease course, } \\
\text { smoking, alcohol and } \\
\text { snuff use }\end{array}$ & $\begin{array}{l}\text { Data on disease } \\
\text { course and sun } \\
\text { exposure }\end{array}$ & $\begin{array}{l}\text { Data on disease } \\
\text { course and } \\
\text { adolescent BMI } \\
\text { (index age }>19 \\
\text { years) }\end{array}$ & $\begin{array}{l}\text { Data on disease } \\
\text { course, DRB1 and } \\
\text { smoking }\end{array}$ & $\begin{array}{l}\text { Data on disease } \\
\text { course, DRB1 and } \\
\text { adolescent BMI }\end{array}$ & $\begin{array}{l}\text { Data on } \\
\text { disease } \\
\text { course, } \\
\text { DRB1 and } \\
\text { EBNA-1 } \\
\text { antibody } \\
\text { levels }\end{array}$ \\
\hline Relapsing-onset MS & 8965 & 7520 & 6840 & 7206 & 6109 & 5899 & 4419 \\
\hline Progressive-onset MS & & 540 & 489 & 517 & 456 & 439 & 398 \\
\hline Controls & 11479 & 11386 & 10590 & 10351 & 6683 & 6526 & 5144 \\
\hline
\end{tabular}

BMI, body mass index; EBNA-1, Epstein-Barr virus nuclear antigen-1; EIMS, epidemiological investigation of multiple sclerosis; GEMS, genes and environment in multiple sclerosis; MS, multiple sclerosis.

In GEMS, cases who fulfilled the McDonald criteria ${ }^{1112}$ were identified from the Swedish National MS registry ${ }^{13}$ and one control per case was randomly selected from the national population register matched for age, sex and residential area at the time of disease onset. Those who did not respond were recorded as nonresponders. No reminders were sent out. The study participants, distinct from those in EIMS, were recruited between November 2009 and November 2011. Ethical approval for both EIMS (04-252/1f and 2012/359-32) and GEMS (2008/1617$31 / 2$ and 2017/1378-31) was obtained from the Regional Ethical Review Board at Karolinska Institutet. All participants provided their informed consent.

In both studies, information regarding environmental exposures and lifestyle factors was collected using a standardised questionnaire. The response rate was 93\% for cases and 73\% for controls in EIMS and 82\% for cases and 66\% for controls in GEMS. All participants in both studies were asked to provide blood samples for genetic and serologic analyses. Blood samples were available for $81 \%$ of the cases and $59 \%$ of the controls. Epstein-Barr virus nuclear antigen-1 (EBNA-1) antibody status was available for participants who had been recruited before August 2013. Table 1 presents the number of cases and controls in each study, and online supplemental table 1 provides further information regarding missing data.

\section{Definition of self-reported exposures Smoking}

Information regarding smoking was obtained by asking about current and previous smoking habits. The year of disease onset in cases was defined as the index year and the corresponding controls were given the same index year. Cases and controls were categorised into current smokers (those who smoked during the index year), previous smokers (those who had stopped smoking prior to the index) and never smokers (those who had never smoked before or during the index year). We also calculated the number of pack years as a measure of the cumulated dose of smoking before the index year. One pack year is defined as 20 cigarettes smoked daily for 1 year.

\section{Snuff use}

Subjects provided information regarding current and previous snuff use. Subjects who reported that they had never smoked, but used snuff before or during the index year was defined as exclusive snuff users. The total number of packages of snuff consumed before the index year was calculated as a measure of the cumulative dose of snuff.

\section{Alcohol consumption}

Incident cases and controls in EIMS were defined as drinkers if they reported alcohol consumption during the year before study inclusion and those who did not drink alcohol were defined as nondrinkers. Prevalent cases and controls in GEMS were categorised into drinkers and nondrinkers based on their alcohol consumption at disease onset. We further categorised the drinkers into the following subgroups based on the sex-specific distribution of alcohol intake in gram per week; nondrinkers, low consumption (below or equal to the median), moderate consumption (above the median, but below or equal to the 75 th percentile) and high consumption (above the 75 th percentile). Low alcohol consumption was defined as $<24 \mathrm{~g} /$ week among women and $<60 \mathrm{~g} /$ week among men; moderate alcohol consumption as 24-89 g/week among women and 60-114 g/ week among men and high alcohol consumption as $>89 \mathrm{~g} /$ week among women and $>114 \mathrm{~g} /$ week among men.

\section{Adolescent body mass index}

Information was obtained regarding current height and body weight at age 20. We calculated body mass index (BMI) at age 20 , by dividing weight in kilograms by height in metres squared. Adolescent BMI was categorised into normal weight $(<25 \mathrm{~kg} /$ $\mathrm{m}^{2}$ ), overweight $\left(25-30 \mathrm{~kg} / \mathrm{m}^{2}\right)$ and obesity $\left(>30 \mathrm{~kg} / \mathrm{m}^{2}\right)$.

\section{Sun exposure}

Sun exposure during the index year was estimated as high or low during the time period (5-year period in EIMS and 10-year period in GEMS) that included the index year. Based on three questions regarding sun exposure (frequency of sun bathing, travelling to a sunnier country and frequency of use of sunbeds) where each answer alternative was reported on a four-point scale, we created a sun exposure index by adding the numbers together, acquiring a value between 3 (the lowest exposure) and 12 (the highest exposure) (online supplemental table 2). Sun exposure was dichotomised into high or low based on the 25 th percentile among controls (5).

\section{Genotyping and serologic analyses}

HLA-A and HLA-DRB1 alleles were determined at four-digit resolution, using the MS replication chip, ${ }^{14}$ an Illumina exome chip to which approximately 90000 custom markers were added, and HLA was then imputed with HLA*IMP:02. ${ }^{15}$ Population stratification was determined by PCA of ancestral informative markers using EIGENSTRAT, and population outliers were removed.

Multiplex serology was used to detect IgG antibodies against the EBNA-1 peptide segment (aa 385-420), ${ }^{16} 17$ which was 
selected from our previous study as the main targeted fragment associated with MS. ${ }^{18}$ Dual-laser flow-based detection was used to quantify the antibodies as units of median fluorescence intensity (MFI). EBNA-1 antibodies were quantified as units of median seroreactivity among controls (4920 MFI) defining groups with high and low EBNA-1 antibody levels.

\section{Statistical analysis}

Each risk factor was analysed separately. Using logistic regression models, exposed and unexposed subjects were compared with regards to relapsing-onset and progressive-onset MS, respectively, by calculating OR with 95\% CIs with adjustment for the matching factors. ${ }^{19}$ We performed both conditional and unconditional analyses of the data. We were able to include a higher number of controls in the unconditional analyses, which, therefore, had increased statistical power. Only the results from the unconditional analyses are presented since these were in close agreement with those from the conditional analyses but had higher precision in terms of more narrow CIs.

We also performed the analyses by study, and measures of association derived from each study were then combined. Specifically, ORs were combined by calculating a weighted average of the study-specific adjusted ORs, where weights were proportional to the inverse of the variance for each OR.

For each risk factor, a trend test for a dose-response relationship regarding exposure level and risk of relapsing and progressive onset MS was performed by using a continuous or categorical variable, as described in the section Definitions of exposures, in a logistic regression model.

Sufficient-cause interactions between DRB1*15:01 and smoking, obesity, high EBNA-1 antibody levels and sun exposure, respectively, were evaluated by estimating departure from additivity of effects using attributable proportion (AP) due to interaction. ${ }^{2021}$ Statistical interaction is scale dependent and presence of interaction on one scale does not necessarily mean presence of interaction on the other. Presence of no interaction between two risk factors (with OR larger than 1) on the additive scale implies negative interaction on the multiplicative scale and presence of no interaction between two risk factors on the multiplicative scale implies that there is positive interaction on the additive scale. Interaction on the additive scale is thought to be more informative from a public health perspective than multiplicative interaction. Further, the sufficient-cause concept that was developed by Rothman et $a l^{20}$ and later expanded by VanderWheele ${ }^{21}$ has improved the understanding between disease causation and interaction, in that, presence of interaction between two causal factors on the additive scale implies that there exists a pathway towards disease where the presence of both risk factors is needed. The AP between two interacting factors reflects the joint effect beyond the sum of the independent effects. Factors associated with reduced risk of disease should be recoded as risk factors when conducting analyses of interaction. ${ }^{22}$ We also calculated the product terms for the interactions between DRB1*15 and each environmental factor in logistic regression models in order to present the interactions on the multiplicative scale.

All analyses were adjusted for study, year of enrollment, age, sex, residential area and ancestry. Residential area was defined as the Swedish county (1 of 21 ) in which the participant lived, and the variable was dichotomised into conurbations (Stockholm, Göteborg, Malmö) and smaller cities. Ancestry was dichotomised into Nordic versus non-Nordic origin. Participants born in Sweden, Norway or Denmark, whose parents had not immigrated from outside these countries, were classified as Nordic.
When examining the impact of a risk factor on relapsing and progressive onset MS, the remaining risk factors were assessed as potential confounding factors. The factors that had no influence on the main results were not included in the final model.

As a sensitivity analysis, we used principal component analysis (PCA) vectors based on 3736 ancestrally informative markers to adjust for population stratification. In this analysis, population outliers were excluded, as were related participants in order to avoid cryptic relatedness. All analyses were conducted using SAS V.9.4.

\section{RESULTS}

Our analyses of risk factors for relapsing-onset and progressiveonset MS included 8060 cases and 11386 controls matched by age, sex and residential area. Among cases with progressiveonset MS $(n=540)$, disease-onset occurred later by approximately a decade, as compared with those with relapsing-onset MS. Characteristics of cases and controls are presented in table 2 and online supplemental table 3 .

\section{Environmental factors associated with relapsing-onset and progressive-onset MS \\ Smoking}

Ever smoking was associated with increased risk of both relapsing-onset MS (OR 1.6, 95\% CI 1.5 to 1.7) and progressiveonset MS (OR 1.9, 95\% CI 1.6 to 2.3). With regards to both clinical phenotypes, current smoking had a greater impact on disease risk than previous smoking (table 3). There were significant trends showing increasing risk of both relapsing-onset and progressive-onset MS with cumulative dose of smoking ( $\mathrm{p}$ values for trend $<0.0001)$.

\section{Snuff use}

Exclusive snuff use was associated with reduced risk of both relapsing-onset MS (OR 0.7, 95\% CI 0.6 to 0.9 ) and progressiveonset MS (OR $0.6,95 \%$ CI 0.4 to 0.9 ).

\section{Alcohol consumption}

When subjects were categorised by their weekly alcohol consumption, those who reported a consumption exceeding the 75 th percentile among controls had a $20 \%$ reduced risk of relapsing-onset MS (OR $0.8,95 \%$ CI 0.7 to 0.9 ) and a $50 \%$ reduced risk of progressive onset MS (OR 0.5, 95\% CI 0.4 to 0.7 ) (table 4). The risk of both relapsing-onset and progressiveonset MS decreased with increasing alcohol consumption ( $p$ values for trend $<0.0001$ and 0.009 , respectively).

\section{Overweight/obesity}

Overweight was associated with a small increased risk of relapsing-onset MS (OR 1.3, 95\% CI 1.2 to 1.4 ) and progressiveonset MS (OR 1.2, 95\% CI 0.8 to 1.6 ), whereas obesity had a more pronounced impact on the risk of disease (OR 1.7, 95\% CI 1.4 to 2.0 for relapsing-onset MS and OR 1.8, 95\% CI 1.0 to 3.2 for progressive-onset MS). There were trends showing that the risks increased with increasing adolescent BMI ( $\mathrm{p}$ values for trends 0.007 and 0.01 , respectively).

\section{Sun exposure}

Low exposure to sun was associated with increased risk of relapsing-onset MS (OR 1.3, 95\% CI 1.2 to 1.4) and progressiveonset MS (OR 1.3, 95\% CI 1.1 to 1.6). The risk of developing either of the clinical phenotypes of MS increased with decreasing exposure to the sun ( $\mathrm{p}$ values for trend $<0.0001$ ). 


\begin{tabular}{|c|c|c|c|}
\hline Exposure & $\begin{array}{l}\text { Relapsing-onset } \\
\text { MS }\end{array}$ & $\begin{array}{l}\text { Progressive-onset } \\
\text { MS }\end{array}$ & Controls \\
\hline N & 7520 & 540 & 11386 \\
\hline Females, n (\%) & $5501(73)$ & $321(59)$ & $8278(73)$ \\
\hline Nordic & $6645(88)$ & 490 (91) & $9974(86)$ \\
\hline $\begin{array}{l}\text { Non-Nordic } \\
\text { European }\end{array}$ & $501(7)$ & $41(8)$ & $875(8)$ \\
\hline Non-European & $374(5)$ & $10(2)$ & $767(7)$ \\
\hline Ever smoking, n (\%) & $4108(55)$ & $332(61)$ & $5106(45)$ \\
\hline $\begin{array}{l}\text { Current smoking, } \\
\mathrm{n}(\%)\end{array}$ & $2670(36)$ & $190(35)$ & $2984(26)$ \\
\hline Past smoking, n (\%) & $1438(19)$ & $142(26)$ & $2122(19)$ \\
\hline $\begin{array}{l}\text { Cumulative dose of } \\
\text { smoking, pack years } \\
\text { (SD) }\end{array}$ & $7.6(8.5)$ & $12.3(11)$ & $7.2(8.6)$ \\
\hline $\begin{array}{l}\text { Exclusive snuff users, } \\
\mathrm{n}(\%)\end{array}$ & $316(4.3)$ & $21(4.0)$ & $604(5.4)$ \\
\hline $\begin{array}{l}\text { No alcohol } \\
\text { consumption, n (\%) }\end{array}$ & $2009(27)$ & $152(28)$ & $3000(26)$ \\
\hline $\begin{array}{l}\text { Low alcohol } \\
\text { consumption, n (\%) }\end{array}$ & $1438(19)$ & $110(20)$ & $2102(18)$ \\
\hline $\begin{array}{l}\text { Moderate alcohol } \\
\text { consumption, } \mathrm{n}(\%)\end{array}$ & $3156(42)$ & $217(40)$ & $4679(41)$ \\
\hline $\begin{array}{l}\text { High alcohol } \\
\text { consumption, n (\%) }\end{array}$ & $917(12)$ & $61(11)$ & 1605 (14) \\
\hline $\begin{array}{l}\text { Normal weight, kg/ } \\
\mathrm{m}^{2} \text { (SD) }\end{array}$ & $6200(89)$ & $461(86)$ & 9720 (89) \\
\hline Overweight, n (\%) & $772(7.7)$ & $40(11)$ & $969(8.9)$ \\
\hline Obesity, n (\%) & $234(3.1)$ & $16(3.3)$ & $226(2.1)$ \\
\hline $\begin{array}{l}\text { Mean sun exposure } \\
\text { index (SD) }\end{array}$ & $6.1(1.8)$ & $5.8(1.7)$ & $6.4(1.8)$ \\
\hline $\begin{array}{l}\text { Low sun exposure, } \\
\mathrm{n}(\%)\end{array}$ & $1818(25)$ & $156(30)$ & 2127 (19) \\
\hline $\begin{array}{l}\text { Mean EBNA-1 } \\
\text { antibody levels (SD) }\end{array}$ & 6821 (3079) & $6232(3173)$ & 4894 (3245) \\
\hline $\begin{array}{l}\text { Median EBNA-1 } \\
\text { antibody levels }\end{array}$ & 6838 & 6166 & 4915 \\
\hline $\begin{array}{l}\text { High EBNA-1 } \\
\text { antibody levels }\end{array}$ & $3463(78)$ & $280(70)$ & $2718(53)$ \\
\hline DRB1 *15:01 positive & $3411(58)$ & $246(56)$ & $1843(28)$ \\
\hline$A^{*} 02: 01$ negative & 3371 (57) & $237(54)$ & 2927 (45) \\
\hline $\begin{array}{l}\text { Age at disease onset } \\
\text { (SD) }\end{array}$ & $32.9(10.0)$ & $42.3(11.0)$ & \\
\hline
\end{tabular}

EBNA-1, Epstein-Barr virus nuclear antigen-1; MS, multiple sclerosis.

EBNA-1 antibody levels

High EBNA-1 antibody levels were associated with increased risk of relapsing-onset MS (OR 3.0, 95\% CI 2.7 to 3.3) and progressive-onset MS (OR 2.0, 95\% CI 1.6 to 2.5). The risk increased with increasing levels of EBNA-1 antibodies ( $p$ values for trend <0.0001).

\section{Gene-environment interactions in the development of relapsing-onset and progressive-onset MS}

Overall, carriers of the DRB1*15:01 allele had an increased risk of developing relapsing-onset MS (OR 3.5, 95\% CI 3.3 to 3.8) and progressive-onset MS (3.3, 95\% CI 2.6 to 4.0). Additive interactions occurred between DRB1*15:01 and both smoking, obesity, EBNA-1 antibody levels and sun exposure with regards to both relapsing-onset and progressive-onset MS (table 5).

The interactions were evaluated by calculating the AP. An AP of, for example, 0.5 indicate that the combined effect of two risk factors was $50 \%$ higher than the sum of the individual effects or, equivalently, that $50 \%$ of the cases among the double exposed are due to the interaction per see.

Combined and pooled analyses of data rendered similar results. The results from the pooled analyses are presented in online supplemental tables 3-6. Terms for multiplicative interaction between DRB1*15:01 and each environmental factor are presented in online supplemental table 7 .

All findings remained similar when the analyses included all subjects, and when they were restricted to participants with Nordic and European ancestry, respectively. Furthermore, our results remained almost identical after excluding population outliers and adjusting the analyses for PCA vectors.

\section{DISCUSSION}

Our findings imply that all environmental and lifestyle factors associated with increased risk of developing MS apply to both relapsing-onset and progressive onset disease. Additive interactions between DRB1*15:01 and environmental factors increase MS risk regardless of the clinical phenotype, indicating that the different phenotypes share common underlying disease mechanisms.

The aetiology and pathogenesis of MS are still not resolved. It has long been debated whether the different clinical disease courses in MS are the consequence of different pathogenic mechanisms, with distinct risk factors, or if all MS clinical phenotypes are variations of a similar underlying pathology, with inflammation and neurodegeneration occurring throughout the disease spectrum. ${ }^{4-7}$ Increasing evidence support the latter hypothesis.

Although a vast majority of MS risk alleles are immunological genes, no definite genetic differences have been found between relapsing and progressive onset MS, indicating that the different clinical phenotypes may be opposite ends of the same disease spectrum, rather than different diseases. ${ }^{9}$ Our observation that the DRB1*15:01 allele is comparably distributed in patients

Table 3 OR with $95 \% \mathrm{Cl}$ of developing relapsing-onset and progressive-onset MS among subjects with different smoking habits

\begin{tabular}{|c|c|c|c|c|c|c|}
\hline \multirow[b]{2}{*}{ Smoking } & \multicolumn{3}{|c|}{ Relapsing-onset MS } & \multicolumn{3}{|c|}{ Progressive-onset MS } \\
\hline & $\mathrm{ca} / \mathrm{co}^{*}$ & aOR $(95 \% \mathrm{CI}) \dagger$ & aOR $(95 \% \mathrm{Cl}) \ddagger$ & $\mathrm{Ca} / \mathrm{Co}^{*}$ & aOR $(95 \% \mathrm{Cl}) \dagger$ & aOR $(95 \% \mathrm{Cl}) \neq$ \\
\hline Never smoking & $3412 / 6280$ & 1.0 (reference) & 1.0 (reference) & $208 / 6280$ & 1.0 (reference) & 1.0 (reference) \\
\hline Ever smoking & $4108 / 5106$ & 1.5 (1.4 to 1.6$)$ & $1.6(1.5$ to 1.7$)$ & $332 / 5106$ & 1.7 (1.4 to 2.0$)$ & 1.9 (1.6 to 2.3$)$ \\
\hline Current smoking & $2670 / 2984$ & 1.7 (1.6 to 1.8$)$ & 1.7 (1.6 to 1.8 ) & $190 / 2984$ & 2.0 (1.7 to 2.5 ) & 2.3 (1.9 to 2.8 ) \\
\hline Past smoking & $1438 / 2122$ & 1.3 (1.2 to 1.5$)$ & 1.4 (1.3 to 1.5$)$ & $142 / 2122$ & 1.3 (1.1 to 1.7$)$ & $1.5(1.2$ to 1.9$)$ \\
\hline
\end{tabular}

*Number of exposed cases and controls.

tAdjusted for study, year of enrolment, age, sex, residential area and ancestry.

¥Adjusted for study, year of enrolment, age, sex, residential area, ancestry, obesity, alcohol consumption, sun exposure habits and snuff use. The analyses are based on 7520 relapsing-onset MS cases, 540 progressive-onset MS cases and 11386 controls.

aOR, adjusted OR; MS, multiple sclerosis. 
Table 4 OR with $95 \% \mathrm{Cl}$ of developing relapsing-onset and progressive-onset MS, among subjects with different alcohol consumption habits

\begin{tabular}{|c|c|c|c|c|c|c|}
\hline \multirow[b]{2}{*}{ Alcohol consumption } & \multicolumn{3}{|c|}{ Relapsing-onset MS } & \multicolumn{3}{|c|}{ Progressive-onset MS } \\
\hline & $\mathrm{ca} / \mathrm{co}^{*}$ & aOR $(95 \% \mathrm{Cl}) \dagger$ & aOR $(95 \% \mathrm{Cl}) \ddagger$ & $\mathrm{Ca} / \mathrm{Co}^{*}$ & aOR $(95 \% \mathrm{Cl}) \dagger$ & aOR $(95 \% \mathrm{Cl}) \ddagger$ \\
\hline None & $2009 / 3000$ & 1.0 (reference) & 1.0 (reference) & $152 / 3000$ & 1.0 (reference) & 1.0 (reference) \\
\hline Low & $1438 / 2102$ & $1.0(0.9$ to 1.1$)$ & $1.0(0.9$ to 1.1$)$ & $110 / 2102$ & 0.7 (0.5 to 0.9$)$ & 0.8 (0.6 to 1.0$)$ \\
\hline Moderate & $3156 / 4679$ & 0.9 (0.8 to 1.0$)$ & $0.9(0.8$ to 1.0$)$ & $217 / 4679$ & 0.7 (0.6 to 0.9$)$ & 0.7 (0.6 to 1.0$)$ \\
\hline High & $917 / 1605$ & 0.7 (0.6 to 0.9$)$ & $0.8(0.7$ to 0.9$)$ & $61 / 1605$ & 0.5 (0.4 to 0.7$)$ & 0.5 (0.4 to 0.7$)$ \\
\hline
\end{tabular}

${ }^{*}$ Number of exposed cases and controls.

†Adjusted for study, year of enrolment, age, sex, residential area and ancestry.

$\ddagger$ Adjusted for study, year of enrolment, age, sex, residential area, ancestry, obesity, smoking, sun exposure habits and snuff use. The analyses are based on 7520 relapsing-onset MS cases, 540 progressive-onset MS cases and 11386 controls.

aOR, adjusted OR; MS, multiple sclerosis.

with relapsing-onset, and progressive MS is in accordance with these results.

According to our findings, environmental and lifestyle risk factors for MS, and their interaction with the DRB1*15:01 allele, also contribute to MS development regardless of the clinical phenotype. This further supports the notion that the different phenotypes share common underlying disease mechanisms. A peripheral immune response targeting the CNS is likely to initiate the disease process, and factors modulating the adaptive immune response may increase or decrease the risk of

Table 5 OR with $95 \% \mathrm{Cl}$ of developing relapsing-onset and progressive-onset MS among subjects categorised by DRB1*15:01 and environmental factors

\begin{tabular}{|c|c|c|c|c|c|c|c|}
\hline \multicolumn{8}{|c|}{ Interaction between DRB1*15:01 and smoking } \\
\hline \multirow[b]{2}{*}{ DRB1*15:01 } & \multirow[b]{2}{*}{ Smoking } & \multicolumn{3}{|c|}{ Relapsing-onset MS } & \multicolumn{3}{|c|}{ Progressive-onset MS } \\
\hline & & $\mathrm{ca} / \mathrm{co}^{*}$ & aOR $(95 \% \mathrm{Cl}) \dagger$ & aOR $(95 \% \mathrm{Cl}) \neq$ & $\mathrm{ca} / \mathrm{co}^{*}$ & aOR $(95 \% \mathrm{Cl}) \dagger$ & aOR $(95 \% \mathrm{Cl}) \ddagger$ \\
\hline- & - & $1109 / 2543$ & 1.0 (reference) & 1.0 (reference) & $71 / 2543$ & 1.0 (reference) & 1.0 (reference) \\
\hline- & + & $1478 / 2248$ & $1.6(1.4$ to 1.8$)$ & 1.7 (1.5 to 1.8$)$ & $132 / 2248$ & $1.8(1.4$ to 2.5$)$ & $2.0(1.5$ to 2.9$)$ \\
\hline+ & - & $1626 / 1002$ & 3.8 (3.4 to 4.2$)$ & $3.6(3.3$ to 4.1$)$ & $96 / 1002$ & $3.4(2.5$ to 4.8$)$ & $3.2(2.3$ to 4.4$)$ \\
\hline+ & + & $1896 / 890$ & $5.2(4.6$ to 5.8$)$ & $5.3(4.7$ to 5.9$)$ & $157 / 890$ & 5.5 (4.1 to 7.5$)$ & $6.0(4.4$ to 8.2$)$ \\
\hline AP & & & $0.2(0.1$ to 0.3$)$ & $0.2(0.1$ to 0.3$)$ & & $0.2(0.02$ to 0.4$)$ & $0.3(0.1$ to 0.5$)$ \\
\hline \multicolumn{8}{|c|}{ Interaction between DRB1*15:01 and obesity } \\
\hline $\mathrm{DRB} 1 * 15: 01$ & Obesity & $\mathrm{ca} / \mathrm{Co}^{*}$ & aOR $(95 \% \mathrm{Cl}) \dagger$ & $\mathrm{aOR}(95 \% \mathrm{Cl}) \S$ & $\mathrm{ca} / \mathrm{Co}^{*}$ & aOR $(95 \% \mathrm{Cl}) \dagger$ & aOR $(95 \% \mathrm{Cl}) \S$ \\
\hline- & - & $2422 / 4595$ & 1.0 (reference) & 1.0 (reference) & $187 / 4595$ & 1.0 (reference) & 1.0 (reference) \\
\hline- & + & $66 / 88$ & $1.4(1.0$ to 1.9$)$ & $1.4(1.0$ to 1.9$)$ & $6 / 88$ & $1.7(0.7$ to 4.3$)$ & $1.6(0.6$ to 4.1$)$ \\
\hline+ & - & $3293 / 1818$ & 3.5 (3.2 to 3.7$)$ & 3.4 (3.1 to 3.6$)$ & $238 / 1818$ & $3.2(2.6$ to 4.0$)$ & 3.1 (2.5 to 3.8$)$ \\
\hline+ & + & $118 / 25$ & 8.7 (5.6 to 13.4$)$ & $8.4(5.4$ to 12.9$)$ & $8 / 25$ & 8.0 (3.4 to 18.8$)$ & 7.4 (2.9 to 17.8$)$ \\
\hline AP & & & $0.6(0.4$ to 0.8$)$ & 0.5 (0.3 to 0.8$)$ & & $0.5(0.1$ to 1.0$)$ & 0.5 (0.01 to 1.0$)$ \\
\hline \multicolumn{8}{|c|}{ Interaction between DRB1*15:01 and EBNA-1 antibody levels } \\
\hline DRB1*15:01 & EBNA-1 lgG levels & $\mathrm{Ca} / \mathrm{Co}^{*}$ & aOR $(95 \% \mathrm{Cl}) \dagger$ & $\mathrm{aOR}(95 \% \mathrm{Cl}) \uparrow$ & $\mathrm{ca} / \mathrm{co}^{*}$ & $\mathrm{aOR}(95 \% \mathrm{Cl}) \dagger$ & $\mathrm{aOR}(95 \% \mathrm{Cl})$ ๆ \\
\hline- & Low & $510 / 1836$ & 1.0 (reference) & 1.0 (reference) & $67 / 1836$ & 1.0 (reference) & 1.0 (reference) \\
\hline- & High & $1284 / 1832$ & $2.5(2.2$ to 2.9$)$ & 2.5 (2.2 to 2.8$)$ & $110 / 1832$ & $1.7(1.2$ to 2.3$)$ & $1.6(1.2$ to 2.2$)$ \\
\hline+ & Low & $446 / 590$ & $2.8(2.3$ to 3.2$)$ & $2.9(2.4$ to 3.4$)$ & $51 / 590$ & 2.(1.7 to 3.6$)$ & 2.4 (1.6 to 3.6$)$ \\
\hline+ & High & $2179 / 886$ & $8.9(7.9$ to 10.1$)$ & 9.1 (8.0 to 10.3$)$ & $170 / 886$ & 5.5 (4.1 to 7.5$)$ & $5.5(4.1$ to 7.5$)$ \\
\hline AP & & & $0.5(0.4$ to 0.6$)$ & $0.5(0.4$ to 0.6$)$ & & $0.4(0.3$ to 0.6$)$ & $0.4(0.3$ to 0.6$)$ \\
\hline \multicolumn{8}{|c|}{ Interaction between DRB1 *15:01 and sun exposure } \\
\hline & & \multicolumn{3}{|c|}{ Relapsing-onset MS } & \multicolumn{3}{|c|}{ Progressive-onset MS } \\
\hline DRB1*15:01 & Sun exposure & $\mathrm{ca} / \mathrm{co}^{*}$ & aOR $(95 \% \mathrm{Cl}) \dagger$ & $\mathrm{aOR}(95 \% \mathrm{Cl})^{* *}$ & $\mathrm{ca} / \mathrm{co}^{*}$ & $\mathrm{aOR}(95 \% \mathrm{Cl}) \dagger$ & $\mathrm{aOR}(95 \% \mathrm{Cl})^{* *}$ \\
\hline- & High & $1921 / 3864$ & 1.0 (reference) & 1.0 (reference) & $155 / 3864$ & 1.0 (reference) & 1.0 (reference) \\
\hline- & Low & $666 / 927$ & $1.4(1.3$ to 1.6$)$ & 1.4 (1.3 to 1.6$)$ & $48 / 927$ & $1.2(0.8$ to 1.7$)$ & 1.1 (0.8 to 1.6$)$ \\
\hline+ & High & $2628 / 1516$ & 3.5 (3.2 to 3.8$)$ & 3.4 (3.1 to 3.7$)$ & $166 / 1516$ & 2.7 (2.2 to 3.5$)$ & 2.7 (2.1 to 3.4$)$ \\
\hline+ & Low & $894 / 376$ & $4.8(4.2$ to 5.5$)$ & 4.8 (4.1 to 5.4$)$ & $87 / 376$ & $5.3(3.9$ to 7.1$)$ & 4.8 (3.4 to 6.2$)$ \\
\hline AP & & & 0.2 (0.1 to 0.4 ) & 0.2 (0.1 to 0.3 ) & & $0.4(0.3$ to 0.6$)$ & $0.4(0.2$ to 0.6$)$ \\
\hline
\end{tabular}

\footnotetext{
${ }^{*}$ Number of exposed cases and controls.
}

tAdjusted for study, year of enrolment, age, sex, residential area and ancestry.

‡Adjusted for study, year of enrolment, age, sex, residential area, ancestry, obesity, alcohol consumption, sun exposure habits, snuff use, HLA-A*02:01 and EBNA-1 antibody status.

$\S A d j u s t e d$ for study, year of enrolment, age, sex, residential area, ancestry, smoking, alcohol consumption, sun exposure habits, snuff use, HLA-A*02:01 and EBNA-1 antibody status.

I|Adjusted for study, year of enrolment, age, sex, residential area, ancestry, smoking, obesity, alcohol consumption, sun exposure habits, snuff use and HLA-A*02:01.

${ }^{* *}$ Adjusted for study, year of enrolment, age, sex, residential area, ancestry, smoking, obesity, alcohol consumption, snuff use, HLA-A*02:01 and EBNA-1 antibody status. aOR, adjusted OR; AP, Attributable proportion due to interaction; MS, multiple sclerosis. 
disease initiation. Potential biological mechanisms behind the association of specific environmental factors with MS risk have been discussed in detail elsewhere. ${ }^{23-25}$

Clinically silent lesions on MRI are often found in patients at the time of the first symptoms of disease, indicative of a preclinical phase of MS of unknown duration. A study of subjects identified by MRI as having asymptomatic disease, who later experienced symptoms consistent with PPMS, showed that the preprogressive phase is characterised by active lesion development that is similar to that in relapsing-remitting $\mathrm{MS}^{26}$

New data also reveal that silent progression, associated with brain atrophy, during the relapsing-remitting phase is common, and independent of relapse activity. ${ }^{27}$ The onset of the clinical progressive phase in MS is dependent on age rather than on the presence or absence of preceding clinical relapses. ${ }^{7}$ Although it remains unexplained why MS would manifest clinically as relapses in some patients, but not in others, patients with progressive onset MS may have had subclinical disease activity at similar ages as patients with preceding clinical relapses.

Our studies were designed as case-control studies and information regarding exposures and lifestyle factors was collected retrospectively. In order to reduce the risk of recall bias, EIMS primarily recruited incident cases of MS, whereas GEMS recruited prevalent cases. However, the relationship between MS and most of the investigated environmental factors had not been investigated to a large extent when our original results were published, ${ }^{28-30}$ and the quality of the reported information would probably not differ between cases and controls. In a validation study among women in the Nurses' Health Study, high correlations were found between recalled and measured weight, with a mean difference of $1.4 \mathrm{~kg} .{ }^{31}$ A possible underreporting of weight in our study would probably not differ by case-control status, especially since there is no association between BMI at disease onset and MS risk. ${ }^{32}$

Since the participants were asked to estimate their sun exposure habits by answering three questions using a four-point scale, we did not have specific information regarding intensity or duration of sun exposure by season, neither did we have information regarding the use of sunscreen. Our categorisation by sun exposure habits is, thus relatively imprecise.

Selection bias was minimised by the population-based design. Since the public healthcare system in Sweden provides equal free of charge access to medical services for all citizens, cases of MS are referred to neurological units, making them eligible to be included in EIMS. Selection bias among controls is probably modest because the prevalence of life style factors, such as smoking and socioeconomic status, among the controls was in close agreement with that of the general population. ${ }^{33}$ The synergistic effects with risk genes also argue against biases in the interpretation of the lifestyle factors, since the HLA alleles are unlikely to determine exposure habits. We, thus, believe that our findings are not affected by bias to a large extent. Since we used a case-control study design, we only show associations between environmental exposures and disease, without being able to confirm causality. Further studies are needed in order to investigate biological mechanisms behind our findings.

In summary, our finding that the same environmental and lifestyle factors affect both relapsing-onset and progressive-onset MS supports the notion that the different clinical MS phenotypes share common underlying disease mechanisms.

Contributors AKH: conception and design of the study, acquisition and analysis of data, drafting the manuscript. JH, TO and LA: conception and design of the study. All authors revised the manuscript and approved the final draft.
Funding The study was supported by grants from the Swedish Research Council (2016-02349); from the Swedish Research Council for Health, Working Life and Welfare (2015-00195 and 2019-00697), the Swedish Brain Foundation (F02020-0077), MS forskningsfonden and NEURO Sweden.

Competing interests $\mathrm{JH}$ received honoraria for serving on advisory boards for Biogen and Novartis and speaker's fees from Biogen, Merck-Serono, Bayer-Schering, Teva and Sanofi-Aventis. He has served as principal investigator for projects sponsored by, or received unrestricted research support from, Biogen, Merck-Serono, TEVA, Novartis and Bayer-Schering. TO received honoraria for advisory boards an unrestricted MS research grants from Biogen, Novartis, Sanofi, Roche and Merck. Alfredsson reports grants from Swedish Research Council, grants from Swedish Research Council for Health Working Life and Welfare, grants from Swedish Brain Foundation, during the conduct of the study; personal fees from Teva, personal fees from Biogene Idec, outside the submitted work.

\section{Patient consent for publication Not required.}

Provenance and peer review Not commissioned; externally peer reviewed.

Data availability statement Data are available upon reasonable request. Anonymised data will be shared by request from any qualified investigator that wants to analyse questions that are related to the published article.

Supplemental material This content has been supplied by the author(s). It has not been vetted by BMJ Publishing Group Limited (BMJ) and may not have been peer-reviewed. Any opinions or recommendations discussed are solely those of the author(s) and are not endorsed by BMJ. BMJ disclaims all liability and responsibility arising from any reliance placed on the content. Where the content includes any translated material, BMJ does not warrant the accuracy and reliability of the translations (including but not limited to local regulations, clinical guidelines, terminology, drug names and drug dosages), and is not responsible for any error and/or omissions arising from translation and adaptation or otherwise.

Open access This is an open access article distributed in accordance with the Creative Commons Attribution 4.0 Unported (CC BY 4.0) license, which permits others to copy, redistribute, remix, transform and build upon this work for any purpose, provided the original work is properly cited, a link to the licence is given, and indication of whether changes were made. See: https://creativecommons.org/ licenses/by/4.01.

\section{ORCID iD}

Anna Karin Hedström http://orcid.org/0000-0002-6612-4749

\section{REFERENCES}

1 Lublin FD, Reingold SC, Cohen JA, et al. Defining the clinical course of multiple sclerosis: the 2013 revisions. Neurology 2014;83:278-86.

2 Koch $M$, Kingwell E, Rieckmann $P$, et al. The natural history of primary progressive multiple sclerosis. Neurology 2009;73:1996-2002.

3 Tremlett H, Zhao Y, Devonshire V, et al. Natural history comparisons of primary and secondary progressive multiple sclerosis reveals differences and similarities. J Neurol 2009;256:374-81.

4 Olerup 0, Hillert J, Fredrikson S, et al. Primarily chronic progressive and relapsing/ remitting multiple sclerosis: two immunogenetically distinct disease entities. Proc Natl Acad Sci U SA 1989;86:7113-7.

5 Antel J, Antel S, Caramanos Z, et al. Primary progressive multiple sclerosis: part of the MS disease spectrum or separate disease entity? Acta Neuropathol 2012;123:627-38.

6 Iwanowski P, Losy J. Immunological differences between classical phenothypes of multiple sclerosis. J Neurol Sci 2015;349:10-14.

7 Kantarci $\mathrm{OH}$. Phases and phenotypes of multiple sclerosis. Continuum 2019;25:636-54.

8 Lassmann $\mathrm{H}$. Pathogenic mechanisms associated with different clinical courses of multiple sclerosis. Front Immunol 2018;9:3116

9 Moutsianas L, Jostins L, Beecham AH, et al. Class II HLA interactions modulate genetic risk for multiple sclerosis. Nat Genet 2015;47:1107-13.

10 McKay KA, Kwan V, Duggan T, et al. Risk factors associated with the onset of relapsing-remitting and primary progressive multiple sclerosis: a systematic review. Biomed Res Int 2015;2015:1-11.

11 Polman CH, Reingold SC, Edan G, et al. Diagnostic criteria for multiple sclerosis: 2005 revisions to the "McDonald Criteria". Ann Neurol 2005;58:840-6.

12 Polman CH, Reingold SC, Banwell B, et al. Diagnostic criteria for multiple sclerosis: 2010 revisions to the McDonald criteria. Ann Neurol 2011;69:292-302.

13 Hillert J, Stawiarz L. The Swedish MS registry - clinical support tool and scientific resource. Acta Neurol Scand 2015;132:11-19.

14 International Multiple Sclerosis Genetics Consortium. Multiple sclerosis genomic MAP implicates peripheral immune cells and microglia in susceptibility. Science 2019;365:eaav7188.

15 Dilthey A, Leslie S, Moutsianas L, et al. Multi-population classical HLA type imputation. PLoS Comput Biol 2013;9:e1002877 
16 Waterboer T, Sehr P, Michael KM, et al. Multiplex human papillomavirus serology based on in situ-purified glutathione S-transferase fusion proteins. Clin Chem 2005;51:1845-53.

17 Brenner N, Mentzer AJ, Butt J, et al. Validation of multiplex serology detecting human herpesviruses 1-5. PLoS One;13:e0209379.

18 Sundqvist $E$, Sundström $P$, Lindén $M$, et al. Epstein-Barr virus and multiple sclerosis: interaction with HLA. Genes Immun 2012;13:14-20.

19 Pearce N. Analysis of matched case-control studies. BMJ 2016;25:i969.

20 Rothman KJ, Greenland S, Lash TL, eds. Modern Epidemiology. 3rd ed. Philadelphia: Lippincott Wolliams \& Wilkins, 2008.

21 VanderWeele TJ. Sufficient cause interactions and statistical interactions. Epidemiology 2009;20:6-13.

$22 \mathrm{Knol} \mathrm{MJ,} \mathrm{VanderWeele} \mathrm{TJ,} \mathrm{Groenwold} \mathrm{RHH,} \mathrm{et} \mathrm{al.} \mathrm{Estimating} \mathrm{measures} \mathrm{of} \mathrm{interaction}$ on an additive scale for preventive exposures. Eur J Epidemiol 2011;26:433-8.

23 Hedström AK. Smoking and its interaction with genetics in MS etiology. Mult Scler 2019;25:180-6. Review.

24 Hedström AK, Olsson T, Alfredsson L. The role of environment and lifestyle in determining the risk of multiple sclerosis. Curr Top Behav Neurosci 2015;26:87-104.

25 Hedström AK, Alfredsson L, Olsson T. Environmental factors and their interactions with risk genotypes in MS susceptibility. Curr Opin Neurol 2016;29:293-8.
26 Kantarci $\mathrm{OH}$, Lebrun C, Siva A, et al. Primary progressive multiple sclerosis evolving from radiologically isolated syndrome. Ann Neurol 2016;79:288-94.

27 University of California, San Francisco MS-EPIC Team, Cree BAC, Hollenbach JA, et al. Silent progression in disease activity-free relapsing multiple sclerosis. Ann Neurol 2019;85:653-66.

28 Hedström AK, Olsson T, Alfredsson L. High body mass index before age 20 is associated with increased risk for multiple sclerosis in both men and women. Mult Scler 2012;18:1334-6.

29 Hedström AK, Hillert J, Olsson T, et al. Nicotine might have a protective effect in the etiology of multiple sclerosis. Mult Scler 2013;19:1009-13.

30 Hedström AK, Hillert J, Olsson T, et al. Alcohol as a modifiable lifestyle factor affecting multiple sclerosis risk. JAMA Neurol 2014;71:300-5.

31 Troy LM, Hunter DJ, Manson JE, et al. The validity of recalled weight among younger women. Int J Obes Relat Metab Disord 1995;19:570-2.

32 Hedström AK, Olsson T, Alfredsson L. High body mass index before age 20 is associated with increased risk for multiple sclerosis in both men and women. Mult Scler 2012;18:1334-6.

33 Internet based information. Available: http://www.scb.se [Accessed 16 Apr 2020]. 